\title{
The Emergence of Ambulatory Measurement of Arterial Stiffness and Central Blood Pressure. A Promising Novelty of Clinical Importance or Just Another Marker?
}

\author{
A. Lazaridis ${ }^{1}$, E. Gkaliagkousi ${ }^{1, *}$, M. Doumas ${ }^{1,2}$, A. Reklou ${ }^{1}$ and A. Karagiannis ${ }^{1}$ \\ ${ }^{1} 2^{\text {nd }}$ Propedeutic Department of Internal Medicine, Aristotle University, Thessaloniki, Greece; ${ }^{2}$ Veteran Administration \\ Medical Center and George Washington University, Washington, DC, USA
}

\begin{abstract}
Whereas brachial blood pressure (BP) is still considered the gold standard for the estimation of cardiovascular risk in all clinical trials and guidelines, scientific interest is shifting towards central hemodynamics and the scientific community is experiencing a whole new revolution with the emergence of novel cardiovascular markers such as the ambulatory measurement of central BP and arterial stiffness. Central BP has already started to demonstrate its superiority over peripheral BP as a better and more reliable predictor of end-organ damage in cardiovascular diseases. Furthermore, ambulatory measurement of central BP and pulse wave velocity are expected to add much more useful information towards a more integrated assessment of cardiovascular risk and profile. However, more research is required before these novel markers could be incorporated in the everyday practice of BP measurement.
\end{abstract}

Keywords: Ambulatory monitoring, arterial stiffness, cardiovascular risk, central blood pressure, pulse wave velocity.

\section{INTRODUCTION}

Cardiovascular disease is the leading cause of death worldwide and hypertension is a major risk factor. Although cardiovascular medicine has presented novelties in the therapeutic field, brachial blood pressure (BP) is still considered the gold standard for screening, diagnosis and management of arterial hypertension and peripheral BP is still used as a major determinant of cardiovascular risk in clinical trials.

However, in the recent years central hemodynamics, namely central Systolic (cSBP) and Diastolic blood pressure (cDBP), pulse pressure (PP) and measurement of arterial stiffness, have emerged as novel parameters of cardiovascular risk, mortality and target organ damage in essential hypertension (EH). As a result, new devices have been invented, shifting cardiovascular research from a peripheral to a more central level. In that sense, ambulatory measurement of arterial stiffness and central blood pressure (cBP) could provide useful information over and above the usual measurements used in the everyday clinical practice.

\section{PATHOPHYSIOLOGY AND MEASUREMENT OF ARTERIAL STIFFNESS}

Arterial stiffness describes a non-compliant artery that is a vessel unable to distend in response to different pressure changes. The two major determinants of arterial stiffness are arterial hypertension and aging. Their etiologic relationship resides in the structural and functional alterations that they provoke to the arterial wall, including smooth muscle

\footnotetext{
*Address correspondence to this author at the Department of Internal Medicine, Aristotle University, Konstantinoupoleos 49 str. Thessaloniki, 546 42, Greece; Tel: +302310 892108; Fax: +302310 835955;

Email: eugalant@yahoo.com
}

hypertrophy, increased collagen deposition, degradation of elastic fibers and endothelial dysfunction [1-5].

The pathophysiological substrate of arterial stiffness lies on the velocity with which pulse wave travels along the arterial tree and the interrelationship between the incident and the reflected wave of the pressure waveform. Every time the heart beats a systole, an incident pulse wave generates at the junction with the aorta and propagates along the arterial tree. Propagation continues unimpeded until the pulse wave meets areas of discontinuity of the arterial wall, mainly the high resistance arterioles, thus generating a reflected wave [6]. In normal, healthy and young individuals where arteries are elastic and compliant, the reflected wave travels back towards the aorta and meets the oncoming incident wave during the early diastole thereby increasing diastolic pressure and facilitating coronary perfusion. However, in adults older than 50 years old and in elderly people, where aging and hypertension progressively stiffen the arteries, a different pattern of circulation exists. The incident wave is reflected in a much earlier point of the arterial tree and its reflected waveform travels much faster along the hardened arterial wall in a way that coincides with the oncoming incident wave during systole. The net result is augmentation of the cSBP and reduction of the diastolic pressure compromising the perfusion of the coronary arteries. At the same time, systolic hypertension increases the afterload of the heart thereby producing left ventricular hypertrophy and in the long term, heart dysfunction [7-12]. Furthermore, increased arterial stiffness is associated with progressive microvascular damage which compromises renal and cerebral function $[13,14]$.

The velocity at which the pulse wave travels along the arterial tree is the most direct marker of arterial stiffness and has been established as the gold standard for its measurement. The most common technique consists of measuring the 
distance that a pulse wave covers between two steady body points (carotid and femoral artery) divided by the time needed to reach these sites under simultaneous electrocardiographic monitoring [15]. The selected arteries provide the advantage of a superficial, easy to access location whereas in-between them, lies almost the whole of the aorta which is the major vessel subject to arterial stiffening. In that Sense, pulse wave velocity (PWV) is a simple, non-invasive, reproducible technique and several lines of evidence have proved its significance as an independent prognostic factor of cardiovascular morbidity and mortality in patients with hypertension, diabetes mellitus type II, end-stage renal disease as well as in the general population [16-25]. The aforementioned value has established PWV as a marker of subclinical organ damage according to the latest guidelines of the European Society of Hypertension and European Society of Cardiology [26].

Despite the important relationship of arterial stiffness and PWV with significant hemodynamic components of the central arteries, paradoxically little research had been done so far in the field of cBP parameters.

\section{FROM PERIPHERAL TO CENTRAL BP}

Peripheral BP measurement has for long been and still is the established technique for evaluating arterial hypertension and cardiovascular risk, although we know that differences between peripheral and cBP exist.

In young healthy subjects cBP is lower compared to peripheral BP due to a physiological phenomenon called PP amplification. At this age, PP travels from the central, elastic arteries towards the smaller, muscular and more resistant arteries of the periphery thereby undergoing an augmentation of its amplitude. As a result, brachial BP can be as high as $30 \mathrm{mmHg}$ more compared to cBP. On the other hand, by aging the opposite effect is observed. Central arteries become stiffer and cSBP increases at a level higher than that of the periphery due to the magnitude of the reflected waves arriving at the heart. In addition, cBP represents more closely and more realistically the true load of the left ventricle because of its proximity to the key organs, including the heart [11, 27-32]. Taking these two factors into account, someone can conclude that the measurement of brachial BP in an elderly individual may not represent the true "hypertensive" load and his total cardiovascular risk because the central burden that strains his heart may be even larger.

The notion that cBP represents the true load of the heart pump and consequently the real cardiovascular risk, has been the epicenter of interest of a growing number of trials. As a matter of fact, much research has focused lately on demonstrating whether central arterial pressure could turn out to be a better marker of target organ damage and whether it could provide more reliable information regarding cardiovascular risk assessment. The first studies to be conducted, included patients with end-stage renal disease and indeed, underlined the role of cBP parameters in predicting all-cause mortality [33-35]. Since then, accumulating scientific evidence has proved that cBP can predict better cardiovascular events and can actually be an independent factor of cardiovascular morbidity and mortality [36-43]. Furthermore, it has been shown that different anti-hypertensive drugs may exert similar im- pact on peripheral BP whereas on the other hand, achieve different levels of cBP reduction [44-51]. Interestingly, various reductions in cBP resulted in different cardiovascular outcomes, an observation that further highlights the role of cBP as a better marker of target organ damage and cardiovascular risk $[42,45,52]$.

Since accumulating evidence points towards a greater necessity for assessing the central hemodynamics, newer, non-invasive techniques for approaching these phenomena have emerged. Apart from piezo-electronic techniques (Complior) and tonometric methods (SphygmoCor), the recent advent of oscillometric devices (Arteriograph, Mobil-ograph) has offered the opportunity to measure peripheral and cBP parameters, including $24 \mathrm{~h}$ monitoring of their variability $[53,54]$.

\section{SIGNIFICANCE OF 24H AMBULATORY MEAS- UREMENT OF ARTERIAL STIFFNESS AND CEN- TRAL BLOOD PRESSURE}

Although research in cardiovascular field has started to demonstrate the superiority of central over peripheral BP, there are characteristics not fully investigated yet, including cBP and PWV variability. In this context, since peripheral BP levels present a circadian rhythm during the day, it seemed reasonable that a similar pattern for cBP and PWV could exist. However, almost all trials conducted so far included BP measurements at resting conditions whereas variability of PWV has never been studied before.

The study by Luzardo et al. was one of the first attempts to assess ambulatory cBP and arterial stiffness parameters. The investigators enrolled 115 volunteers between 28 and 64 years old from their working enviroment. Although they were not a representative sample of the general population, the volunteers underwent tonometric and oscillometric measurements of arterial stiffness and cBP parameters under resting and ambulatory conditions. Measurements were performed using the validated Sphygmocor and Mobil-O-graph devices. Despite slight differences between cPP and PWV values among the two methods, the investigators proved that ambulatory, non-invasive measurement of cBP is a feasible procedure. Nevertheless, the study focused on comparing the values recorded between a tonometric and an oscillometric device and did not correlate possible diurnal changes of cBP to the established changes of peripheral BP. In addition, the ambulatory measurement of cBP did not include early morning and late night measurements, two time periods where the most important pathophysiologic alterations in peripheral BP take place [55].

More recently, Williams and his colleagues conducted the first multicenter, randomized, controlled, clinical trial in order to assess the $24 \mathrm{~h}$ circadian profile of cBP. In addition, the investigators have been the pioneers in comparing, simultaneously, ambulatory cBP changes with the diurnal variation of peripheral BP. For the purposes of the study, the investigators enrolled 171 men and women with a mean age of 53 years old and a history of EH. After a wash-out period, participants were randomized into two treatment groups receiving either a direct renin inhibitor or an angiotensin receptor blocker. At the beginning and at the end of the study, ambulatory peripheral $\mathrm{BP}$ and $\mathrm{cBP}$ parameters were meas- 
ured using a conventional, cuff-based, oscillometric device (Spacelabs) and a tonometric ambulatory BP monitoring device (BPro) at the same time. The study demonstrated that cBP changes throughout the day exhibit a similar pattern of variability just like the diurnal fluctuation of brachial BP. The observed diurnal pattern of both central and peripheral pressure remained the same even after administration of BP lowering agents suggesting that BP reduction does not play a role in between pressure's inter-variability. However, of major interest was the observation that $\mathrm{cBP}$ levels remained lower than those of peripheral pressure for the whole $24 \mathrm{~h}$ period whereas, and more significantly, exhibited a lower nocturnal dipping pattern compared to that of brachial pressure [56]. Whether this phenomenon is just a normal consequence of sleep or whether there are other implicating factors remains unknown and needs further investigation due to its apparent major clinical importance. Given the fact that the incidence of cardiovascular events is higher in non-dipper hypertensive individuals [26], someone could conclude that the less pronounced dipping profile of $\mathrm{cBP}$ could have a much more adverse impact on cardiovascular outcomes. In that sense, central pressure and its fluctuations could represent a new therapeutic target emphasizing the need for further research in the field of ambulatory monitoring of $\mathrm{cBP}$.

Another novel observation derived from the ambulatory monitoring of cBP, is the gradual decline of the difference between brachial and cSBP during the approach of night (with cBP falling less as mentioned above) as opposed to its sharp increase at the time of waking in the morning [56]. Until larger-scale trials come into sight, the phenomenon will continue to be under investigation.

Whereas cBP variability has started to be in the epicenter of scientific interest, with the first trials coming up with notable, initial observations, ambulatory measurement of PWV continues to be a virgin field. Remarkably, no trial has consistently studied so far the variations of PWV throughout the day and as matter of fact, no correlations have been made between the diurnal fluctuation of PWV (if such a pattern exists) and the variability of peripheral or $\mathrm{cBP}$. A limiting factor against ambulatory arterial stiffness measurement seems to be hydrostatic pressure. When moving from the supine to an upright position, hydrostatic pressure across the aorta increases, thereby creating a pressure gradient. Taking into account the fact the PWV depends heavily on arterial pressure, someone can conclude that variations of BP during postural movements could negatively affect the precise measurement of arterial stiffness parameters. The observed obstacle is one of the reasons why efforts to obtain ambulatory PWV measurements are still confined to a very rudimental, experimental level $[57,58]$. In this context, until more reliable methods for the ambulatory measurement of PWV come up, diurnal variation of arterial stiffness and its possible applications - implications will continue to be a promising field of cardiovascular research.

\section{CONCLUSIONS}

Whereas peripheral BP continues to be the point of reference of all algorithms and guidelines regarding arterial hypertension and cardiovascular risk, it seems reasonable that in the very near future measurement of cBP will play a major role in cardiovascular risk stratification and treatment.
Mounting evidence from large-scale trials has demonstrated the significance of cBP as a better marker of target organ damage and consequently as a more reliable predictor of cardiovascular morbidity and mortality. In addition, it has been demonstrated that antihypertensive treatment can provoke different changes in cBP parameters consequently changing cardiovascular outcomes. These observations could revolutionize our therapeutic strategies making arterial stiffness and cBP the primary therapeutic targets.

However, more research is needed before applying cBP parameters into every day clinical practice. The advent of ambulatory monitoring of cBP and probably, in the long term of arterial stiffness, will be a determining factor in the effort to understand the masked properties of central hemodynamic components. With only a few trials published so far, it is undoubtedly a virgin field for future cardiovascular novelties.

\section{CONFLICT OF INTEREST}

The author(s) confirm that this article content has no conflicts of interest.

\section{ACKNOWLEDGEMENT}

Declared none.

\section{REFERENCES}

[1] Avolio A, Jones D, Tafazzo - Shadpour M. Quantification of alteration in structure and function of elastin in the arterial media. Hypertension 1998; 32(1): 170-5.

[2] McEniery CM, Wallace S, Mackenzie IS, et al. Endothelial function is associated with pulse pressure pulse wave velocity, and augmentation index in healthy humans. Hypertension 2006; 48(4): 602-8.

[3] Roman MJ, Saba PS, Pini R, et al. Parallel cardiac and vascular adaptation in hypertension. Circulation 1992; 86(6): 1909-18.

[4] Laurent S, Boutouyrie P, Lacolley P. Structural and genetic bases of arterial stiffness. Hypertension 2005; 45(6): 1050-5.

[5] Tziomalos K, Athyros VG, Karagiannis A, Mikhailidis DP. Endothelial function, arterial stiffness and lipid lowering drugs. Expert Opin Ther Targets 2007; 11(9): 1143-60.

[6] Nichols WW, O'Rourke. Wave reflections. McDonald's Blood Flow in Arteries: Theoretic, Experimental and Critical Principles London: Arnold. 1998.

[7] Franklin SS, Gustin W 4th, Wong ND, et al. Hemodynamic patterns of age-related changes in blood pressure. The Framingham Heart Study. Circulation 1997; 96(1): 308-15.

[8] Kelly RP, Tunin R, Kass DA. Effect of reduced aortic compliance on cardiac efficiency and contractile function of in situ canine left ventricle. Circ Res 1992; 71(3): 490-502.

[9] Levy D, Larson MG, Vasan RS, Kannel WB, Ho KK. The progression from hypertension to congestive heart failure. JAMA 1996; 275(20): 155762.

[10] Izzo JL Jr, Shykoff BE. Arterial stiffness: clinical relevance, measurement, and treatment. Rev Cardiovasc Med 2001; 2(1): 29-34, 37-40.

[11] Mitchell GF, Parise H, Benjamin EJ, et al. Changes in arterial stiffness and wave reflection with advancing age in healthy men and women: the Framingham Heart Study. Hypertension 2004; 43: $1239-45$.

[12] Mitchell GF. Effects of central arterial aging on the structure and function of the peripheral vasculature implications for end-organ damage. J Appl Physiol 2008; 105(5): 1652-60.

[13] O'Rourke MF, Safar ME. Relationship between aortic stiffening and microvascular disease in brain and kidney: cause and logic of therapy. Hypertension 2005; 46(1): 200-4.

[14] Mitchell GF. Arterial Stiffness and Wave Reflection: Biomarkers of Cardiovascular Risk. Artery Res 2009; 3(2): 56-64. 
[15] Oliver JJ, Webb DJ. Noninvasive assessment of arterial stiffness and risk of atherosclerotic events. Arterioscler Thromb Vasc Biol 2003; 23(4): 554-66

[16] Laurent S, Cockcroft J, Van Bortel L, Boutouyrie P, Giannattasio C, Hayoz D, et al. Expert consensus document on arterial stiffness: methodological issues and clinical applications. Eur Heart J 2006; 27: 2588-605.

[17] Laurent S, Boutouyrie P, Asmar R, Gautier I, Laloux B, Guize L, et al. Aortic Stiffness is an independent predictor of all-cause and cardiovascular mortality in hypertensive patients. Hypertension 2001; 37: 1236-1241.

[18] Choi CU, Park EB, Suh SY, et al. Impact of aortic stiffness on cardiovascular disease in patients with chest pain: assessment with direct intra-arterial measurement. Am J Hypertens 2007; 20(11): 1163-9.

[19] Cruickshank K, Riste L, Anderson SG, et al. Aortic pulse-wave velocity and its relationship to mortality in diabetes and glucose intolerance: an integrated index of vascular function? Circulation 2002; 106(16): 2085-90.

[20] Mattace-Raso FU, van der Cammen TJ, Hofman A, et al. Arterial stiffness and risk of coronary heart disease and stroke: the Rotterdam Study. Circulation 2006; 113(5): 657-63.

[21] Shokawa T, Imazu M, Yamamoto $\mathrm{H}$, et al. Pulse wave velocity predicts cardiovascular mortality: findings from the Hawaii-Los Angeles-Hiroshima study. Circ J 2005; 69(3): 259-64.

[22] Sutton-Tyrrell K, Najjar SS, Boudreau RM, et al.; Health ABC Study. Elevated aortic pulse wave velocity, a marker of arterial stiffness, predicts cardiovascular events in well-functioning older adults. Circulation 2005; 111(25): 3384-90.

[23] Willum-Hansen T, Staessen JA, Torp-Pedersen C, et al. Prognostic value of aortic pulse wave velocity as index of arterial stiffness in the general population. Circulation 2006; 113(5): 664-70.

[24] Vlachopoulos C, Aznaouridis K, Stefanadis C. Prediction of cardiovascular events and all-cause mortality with arterial stiffness: a systematic review and meta-analysis. J Am Coll Cardiol 2010; 55(13): 1318-27.

[25] Katsiki N, Koumaras C, Athyros VG, Karagiannis A. Thinking beyond traditional cardiovascular risk factors: the role of arterial stiffness in targeting residual risk. Angiology 2012; 63(1): 9-11.

[26] Mancia G, Fagard R, Narkiewicz K, et al. List of authors Task Force Members: $2013 \mathrm{ESH} / \mathrm{ESC}$ Guidelines for the management of arterial hypertension: The Task Force for the management of arterial hypertension of the European Society of Hypertension (ESH) and of the European Society of Cardiology (ESC). J Hypertens 2013; 31(7): 1281-357.

[27] Wilkinson IB, Franklin SS, Hall IR, Tyrrell S, Cockcroft JR. Pressure amplification explains why pulse pressure is unrelated to risk in young subjects. Hypertension 2001; 38(6): 1461-6.

[28] Boutouyrie P, Laurent S, Benetos A, Girerd XJ, Hoeks AP, Safar ME. Opposing effects of ageing on distal and proximal large arteries in hypertensives. J Hypertens Suppl 1992; 10(6): S87-91.

[29] Van der Heijden-Spek JJ, Staessen JA, Fagard RH, Hoeks AP, Boudier HA, van Bortel LM. Effect of age on brachial artery wall properties differs from the aorta and is gender dependent: a population study. Hypertension 2000; 35(2):637- 42.

[30] O'Rourke MF, Vlachopoulos C, Graham RM. Spurious systolic hypertension in youth. Vasc Med 2000; 5(3): 141-5.

[31] Pauca AL, Wallenhaupt SL, Kon ND, Tucker WY. Does radial artery pressure accurately reflect aortic pressure? Chest 1992; 102(4):1193-8.

[32] Avolio AP, Van Bortel LM, Boutouyrie P, et al. Role of pulse pressure amplification in arterial hypertension: experts' opinion and review of the data. Hypertension 2009; 54(2): 375-83.

[33] Safar ME, Blacher J, Pannier B, et al. Central pulse pressure and mortality in end-stage renal disease. Hypertension 2002; 39(3): 735-8.

[34] Protogerou AD, Papaioannou TG, Blacher J, Papamichael CM, Lekakis JP, Safar ME. Central blood pressures: do we need them in the management of Cardiovascular disease? Is it a feasible therapeutic target? J Hypertens 2007; 25(2): 265-72.

[35] London GM, Blacher J, Pannier B, Guérin AP, Marchais SJ, Safar ME. Arterial wave reflections and survival in end-stage renal failure. Hypertension 2001; 38(3): 434-8.

[36] Agabiti-Rosei E, Mancia G, O'Rourke MF, et al. Central blood pressure measurements and antihypertensive therapy: a consensus document. Hypertension 2007; 50(1): 154-60.
[37] Roman MJ, Devereux RB, Kizer JR, et al. High central pulse pressure is independently associated with adverse cardiovascular outcome the strong heart study. J Am Coll Cardiol 2009; 54(18): $1730-4$.

[38] Wang KL, Cheng HM, Chuang SY, et al. Central or peripheral systolic or pulse pressure: which best relates to target organs and future mortality? J Hypertens 2009; 27(3): 461-7.

[39] Chirinos JA, Zambrano JP, Chakko S, et al. Aortic pressure augmentation predicts adverse cardiovascular events in patients with established coronary artery disease. Hypertension 2005; 45(5): 9805.

[40] Vlachopoulos C, Aznaouridis K, O'Rourke MF, Safar ME, Baou K, Stefanadis C. Prediction of cardiovascular events and all cause mortality with central haemodynamics: a systematic review and meta-analysis. Eur Heart J 2010; 31(15): 1865-71

[41] Jankowski P, Kawecka-Jaszcz K, Czarnecka D, et al; Aortic Blood Pressure and Survival Study Group. Pulsatile but not steady component of blood pressure predicts cardiovascular events in coronary patients. Hypertension 2008; 51(4): 848-55.

[42] Roman MJ, Devereux RB, Kizer JR, et al. Central pressure more strongly relates to vascular disease and outcome than does brachial pressure: the Strong Heart Study. Hypertension 2007; 50(1): 197-203.

[43] Safar ME, Jankowski P. Central blood pressure and hypertension: role in cardiovascular risk assessment. Clin Sci (Lond) 2009; 116(4): 273-82.

[44] London GM, Asmar RG, O'Rourke MF, Safar ME. REASON Project Investigators. Mechanism(s) of selective systolic blood pressure reduction after a low-dose combination of perindopril/indapamide in hypertensive subjects: comparison with atenolol. J Am Coll Cardiol 2004; 43(1): 92-9.

[45] Williams B, Lacy PS, Thom SM, et al; CAFE Investigators; AngloScandinavian Cardiac Outcomes Trial Investigators; CAFÉ Steering Committee and Writing Committee. Differential impact of blood pressure-lowering drugs on central aortic pressure and clinical outcomes: principal results of the Conduit Artery Function Evaluation (CAFE) study. Circulation 2006; 113(9): 1213-25.

[46] Safar ME, Blacher J, Protogerou A, Achimastos A. Arterial stiffness and central hemodynamics in treated hypertensive subjects according to brachial blood pressure classification. J Hypertens 2008; 26(1): 130-7.

[47] Vlachopoulos C, Hirata K, O'Rourke MF. Pressure-altering agents affect central aortic pressures more than is apparent from upper limb measurements in hypertensive patients: the role of arterial wave reflections. Hypertension 2001; 38(6): 1456-60.

[48] Hirata K, Vlachopoulos C, Adji A, O'Rourke MF. Benefits from angiotensin-converting enzyme inhibitor 'beyond blood pressure lowering': beyond blood pressure or beyond the brachial artery? J Hypertens 2005; 23(3): 551-6.

[49] Dhakam Z, McEniery CM, Yasmin, CJR, Brown MJ, Wilkinson IB. Atenolol and eprosartan: differential effects on central blood pressure and aortic pulse wave velocity. Am J Hypertens 2006; 19(2): 214-9

[50] Mackenzie IS, McEniery CM, Dhakam Z, Brown MJ, Cockcroft JR, Wilkinson IB. Comparison of the effects of antihypertensive agents on central blood pressure and arterial stiffness in isolated systolic hypertension. Hypertension 2009; 54(2): 409-13.

[51] Koumaras C, Tzimou M, Stavrinou E, et al. Role of antihypertensive drugs in arterial "de-stiffening" and central pulsatile hemodynamics. Am J Cardiovasc Drugs 2012; 12(3): 143-56.

[52] Kelly RP, Gibbs HH, O'Rourke MF, et al. Nitroglycerin has more favorable effects on left ventricular afterload than apparent from measurement of pressure in a peripheral artery. Eur Heart J 1990 11(2): 138-44

[53] Papaioannou TG, Protogerou A, Stefanadis C. Comparison between Mobil-O-Graph and the SphygmoCor device for central systolic blood pressure estimation: consensus is required for validation protocols. Blood Press Monit 2012; 17(6): 259-60.

[54] Weiss W, Gohlisch C, Harsch-Gladisch C, Tölle M, Zidek W, van der Giet M. Oscillometric estimation of central blood pressure: validation of the Mobil-O-Graph in comparison with the SphygmoCor device. Blood Press Monit 2012; 17 (3): 128-31

[55] Luzardo L, Lujambio I, Sottolano M, et al. 24-h ambulatory recording of aortic pulse wave velocity and central systolic augmentation: a feasibility study. Hypertens Res 2012; 35(10):980-7. 
[56] Williams B, Lacy PS, Baschiera F, Brunel P and Düsing R. Clinical Trial: The Ambulatory Central Aortic Pressure (AmCAP) Study Blood Pressure and the Impact of Blood Pressure Treatment in a Randomized Controlled Novel Description of the 24-Hour Circadian Rhythms of Brachial Versus Central Aortic. Hypertension 2013; 61:1168-1176.

[57] McCombie DB, Reisner AT, Asada HH. Adaptive blood pressure estimation from wearable PPG sensors using peripheral artery pulse wave velocity measurements and multi-channel blind identification of local arterial dynamics. Conf Proc IEEE Eng Med Biol Soc 2006; 1:3521-4.

[58] Solà J, Chételat O, Sartori C, Allemann Y, Rimoldi SF. Chest pulse-wave velocity: a novel approach to assess arterial stiffness. IEEE Trans Biomed Eng 2011; 58(1): 215-23.

Received: September 21, 2013

Revised: September 25, 2013

Accepted: September 25, 2013

(C) Lazaridis et al.; Licensee Bentham Open.

This is an open access article licensed under the terms of the Creative Commons Attribution Non-Commercial License (http://creativecommons.org/licenses/by-nc/3.0/) which permits unrestricted, non-commercial use, distribution and reproduction in any medium, provided the work is properly cited. 